\title{
TITLE:
}

\section{$<$ News $>$ Massive New Rainforest Reserve Established in the Democratic Republic of Congo}

\section{$\operatorname{AUTHOR}(\mathrm{S})$ :}

Hurley, Michael

\section{CITATION:}

Hurley, Michael. <News> Massive New Rainforest Reserve Established in the Democratic Republic of Congo. Pan Africa News 2007, 14(2): 17-20

ISSUE DATE:

2007-12

URL:

http://hdl.handle.net/2433/143484

\section{RIGHT:}

Copyright (C) Pan Africa News. 


\section{<NEWS>}

Massive New Rainforest Reserve Established in the Democratic Republic of Congo

Michael Hurley

Bonobo Conservation Initiative
The Bonobo Conservation Initiative (BCI) joins the government of the Democratic Republic of Congo (DRC) in announcing the creation of the new Sankuru Nature Reserve, a huge rainforest area harboring the endangered bonobo, a great ape most closely related to humans. Larger than the state of Massachusetts, the new reserve encompasses 11,803 square miles of tropical rainforest, extremely rich in biodiversity. 

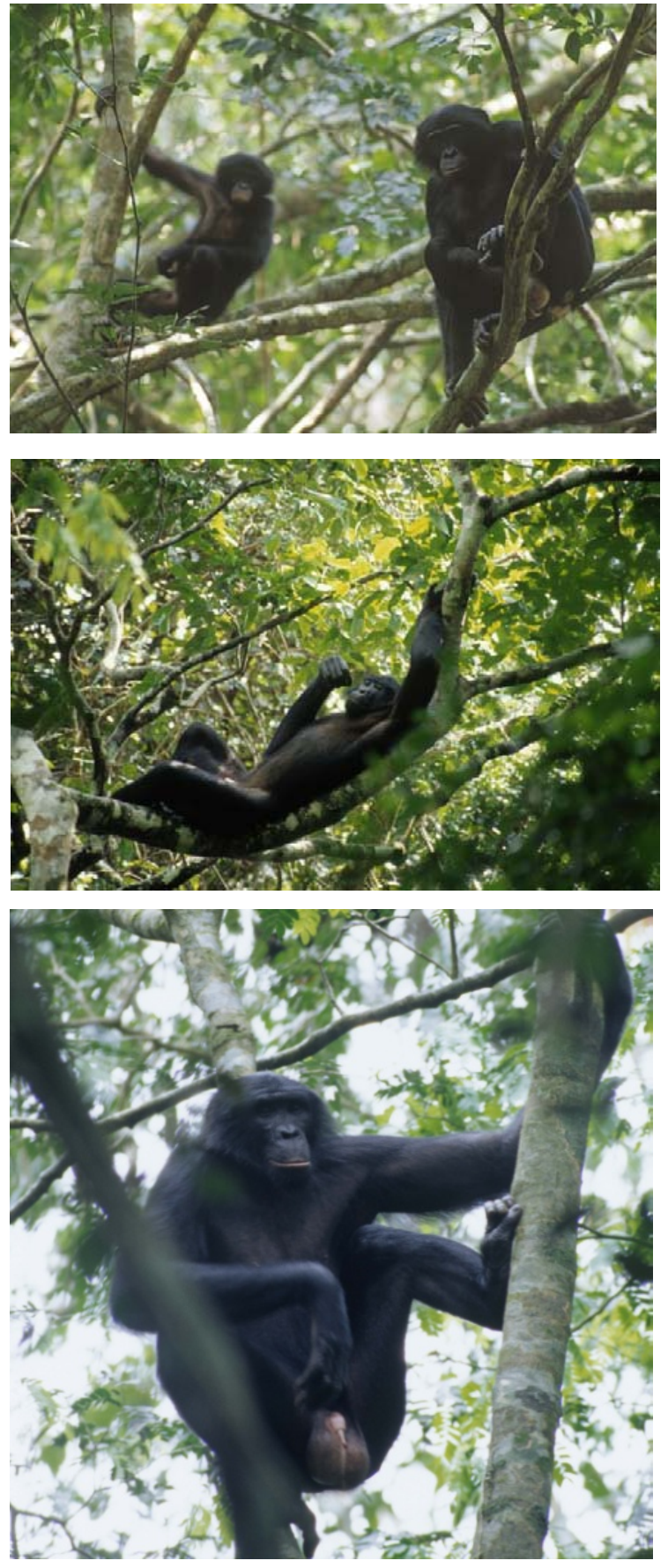

Fig. 1 Wild bonobos of the Kokolopori Reserve, in the Central Congo Basin. Photos by Jeffry Oonk.

"This is a monumental step towards saving a significant portion of the world's second largest rainforest, of critical importance to the survival not only of humankind's closest great ape relative, the bonobo, but to all life on earth given the increasing threat of climate change," said Sally Jewell Coxe, president and co-founder of the Bonobo Conservation Initiative.

The Sankuru region was hit very hard during the recent war in the Congo, which devastated the local people and claimed four million lives -- more than any war since WWII. In addition to the critical environmental challenges presented by unsustainable hunting, the humanitarian crisis must also be addressed. "The people of Sankuru rely on the forest for every aspect of their livelihood. Helping them to develop new economic opportunities apart from the bushmeat trade is one of the most urgent priorities," Coxe said.

In danger of extinction, bonobos (Pan paniscus) were the last great ape to be discovered and are the least known great ape species. Found only in the DRC, bonobos inhabit the heart of the Congo Basin, Africa's largest rainforest, which is threatened by the onslaught of industrial logging. Bonobos are distinguished by their peaceful, cooperative, matriarchal society, remarkable intelligence, and sexual nature. Other than humans, bonobos are the only primates known to have sex not only for procreation, but also for pleasure and conflict resolution -- and with members of either sex. They serve as a powerful flagship both for conservation and for peace.

In addition to the bonobo, the Sankuru Reserve contains the okapi (Okapia johnstoni), an exotic short necked forest giraffe also endemic to the DRC, but not previously found outside of their known range far to the northeast. Survey teams from the Congo's Center for Research in Ecology and Forestry (CREF) sponsored by BCI made this exciting discovery. Sankuru also contains elephants, which have been hunted out in many other areas of the Congo forest, plus at least 10 other species of primates, including the rare owl faced monkey and blue monkey.

The wildlife is under intense pressure from organized hunting for the commercial bushmeat trade. The report from the Congolese Institute for Conservation of Nature (ICCN) on its recent expedition to the area states that "the ecocide must be stopped" and recommends immediate action to protect this invaluable ecosystem and watershed. The DRC Minister of the 

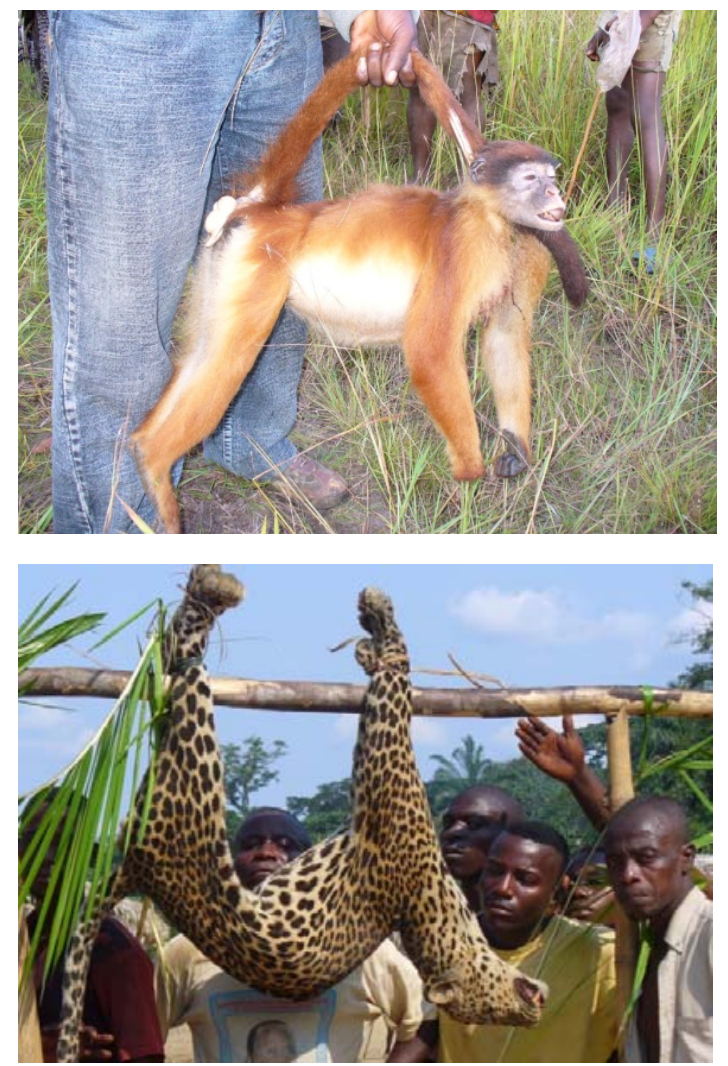

Fig. 2 Bushmeat. All 11 species of primates in Sankuru are heavily hunted for food and income (above). In DRC, other wild animals such as leopard (below) are also victimized by bushmeat hunting that is an important source of food and revenue and is a serious threat in the region. Photos by Bonobo Conservation I nitiative.

Environment, Didace Pembe Bokiaga, who officially declared the new reserve, said, "This increases the total area of protected land in the DRC to $10.47 \%$, bringing us closer to our goal of $15 \%$. We are proud that the Sankuru Reserve is being created in the framework of community participative conservation...and will be zoned to guarantee the rights of the local population."

Andre Tosumba, director of BCI's Congolese NGO partner, ACOPRIK (Community Action for the Primates of Kasai), led the successful local effort to protect Sankuru. "When I saw the extent to which people were hunting bonobos, okapi, and elephants, we began to sensitize them to realize the value of these animals," he said. "Once they came to understand, the people themselves decided to stop hunting these precious species

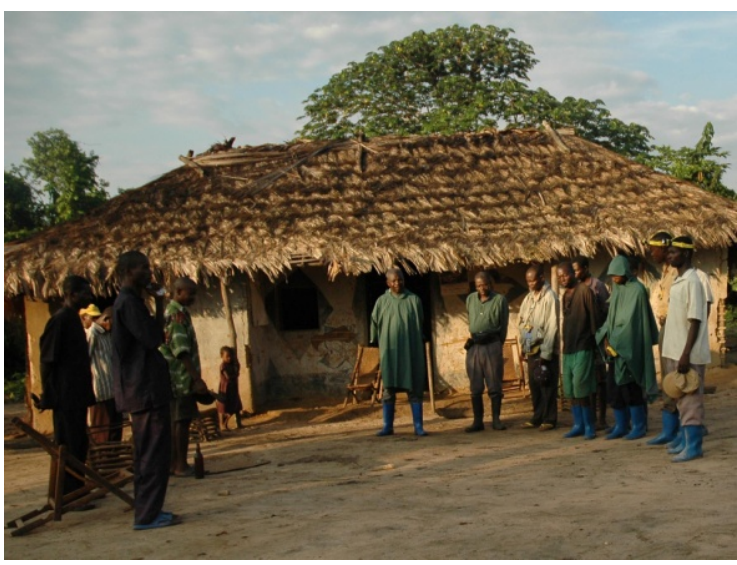

Fig. 3 Sankuru teams. Local teams are trained and equipped to participate in surveys and monitoring programs. Photo by Bonobo Conservation Initiative.

and to create a reserve to protect their forest. BCI has helped ACOPRIK and the local people at every step of the way...we call on the international community to join our effort."

Protecting Sankuru Reserve's forest will contribute significantly to mitigating global warming. Approximately $20 \%$ of annual green house gas emissions come from deforestation and other land-use change. Keeping this rich tropical forest intact will make an important contribution to global efforts to reduce emissions while simultaneously conserving biodiversity. The Sankuru Reserve stores up to 660 million tons of carbon, which if released by deforestation would emit up to 2 billion tons of carbon dioxide, comparable to emissions from $38,000,000$ cars per year for 10 years.

"This is a huge victory for bonobo and rainforest conservation," Coxe said. "However our work has just begun. Now we need investment to successfully manage the reserve. And, other areas need to be protected to ensure the long-term survival of the bonobo and the integrity of the Congo rainforest." The Sankuru Reserve is the southern anchor for a constellation of linked, community-based reserves being developed by BCI in the Bonobo Peace Forest, a project supported by DRC President Joseph Kabila since its inception in 2002.

The Bonobo Conservation Initiative $(\mathrm{BCI})$ is a nonprofit 501(c)(3) organization dedicated to the survival 
of the highly endangered bonobo (Pan paniscus) and its rainforest habitat in the Congo Basin. BCI works with indigenous Congolese people through cooperative conservation and community development programs and the government of the DRC to establish new protected areas and to safeguard bonobos wherever they are found. BCI has been selected as a featured charity in the Catalogue for Philanthropy for excellence, innovation and cost-effectiveness.

Initial support for this project has been provided by the Great Ape Conservation Fund, administered by the US Fish and Wildlife Service in collaboration with USAID's Central African Regional Program for the Environment.

Editor's Note: This report originally appeared in YubaNet.com on November 16, 2007, and is reproduced here by courtesy of Mr. Michael Hurley, Executive Director of Bonobo Conservation Initiative. 